\title{
Genes, oxidative stress, and the risk of chronic obstructive pulmonary disease
}

\author{
Hiroshi Koyama, *Duncan M Geddes
}

Ion Transport Unit, National Heart and Lung Institute, Imperial College, London SW3 6LR, and *Department of Respiratory Medicine, Royal Brompton Hospital, London SW3 6NP, UK

Introductory article

Association between polymorphism in gene for microsomal epoxide hydrolase and susceptibility to emphysema

CAD Smith, DJ Harrison

Background. The first-pass metabolism of foreign compounds in the lung is an important protective mechanism against oxidative stress. We investigated whether polymorphisms in the gene for microsomal epoxide hydrolase (mEPHX), an enzyme involved in this protective process, had any bearing on individual susceptibility to the development of chronic obstructive pulmonary disease (COPD) and emphysema. Methods. We designed PCR-based genotyping assays to detect variant forms of mEPHX that confer slow and fast activity. We used these assays to screen 203 blood-donor controls and groups of patients with asthma $(n=57)$, lung cancer $(n=50), \operatorname{COPD}(n=68)$, and emphysema $(n=94)$, who were attending specialised clinics in Edinburgh, UK. Findings. The proportion of individuals with innate slow mEPHX activity (homozygotes) was significantly higher in both the COPD group and the emphysema group than in the control group (COPD 13 [19\%] vs control 13 [6\%]; emphysema 21 [22\%] vs 13 [6\%]). The odds ratios for homozygous slow activity versus all other phenotypes were 4.1 (95\% Cl 1.8-9.7) for COPD and 5.0 (2.3-10.9) for emphysema. Interpretation. Genetic polymorphisms in xenobiotic enzymes may have a role in individual susceptibility to oxidant-related lung disease. Epoxide derivatives of cigarette-smoke components may be the cause of some of the lung damage characteristic of these diseases. (Lancet 1997;350:630-33)

Chronic obstructive pulmonary disease (COPD) is one of the major causes of premature death in industrialised countries. While its primary pathology is pulmonary emphysema together with narrowing and obliteration of airways, COPD remains a clinical diagnosis characterised by chronic airflow limitation which progresses slowly over a period of years and is largely irreversible. The majority of cases are a consequence of chronic cigarette smoking and are thus preventable. However, only a relatively small proportion of smokers develop symptomatic disease. ${ }^{2}$ As a consequence, there has been considerable interest in identifying those who are most susceptible, and the mechanisms of their susceptibility. A number of studies indicate that genetic factors con-

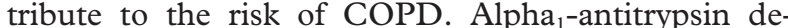
ficiency is already well recognised and twin studies have suggested the presence of other undetermined genetic factors. ${ }^{3-6}$ Identification of these genetic components could provide useful insights into the pathogenesis of COPD in the same way as did recognition of the association between $\alpha_{1}$-antitrypsin deficiency and COPD. ${ }^{7}$ This association, together with the fact that emphysema can be produced experimentally by intratracheal instillation of papain, led to the protease-antiprotease hypothesis of pulmonary emphysema.

The introductory article contributes further to the debate. It suggests that genetic susceptibility to oxidative stress may also confer a risk for the development of COPD. This implies that oxidant-antioxidant imbalance, like protease-antiprotease imbalance, may be important in investigators have implicated oxidant-antioxidant interaction in the pathogenesis of smoking induced COPD. ${ }^{910}$ In brief, smoking increases alveolar oxidants, in part because cigarette smoke itself contains an enormous number of free radicals and in part because it increases the number of inflammatory cells in alveoli which spontaneously release oxidants. These oxidants inactivate $\alpha_{1}$-antitrypsin and other protease inhibitors such as secretory leukoprotease inhibitor. Furthermore, the recruited inflammatory cells also increase the protease burden, thus tipping the protease-antiprotease balance further towards the protease side. Moreover, oxidants in cigarette smoke can directly damage com- 


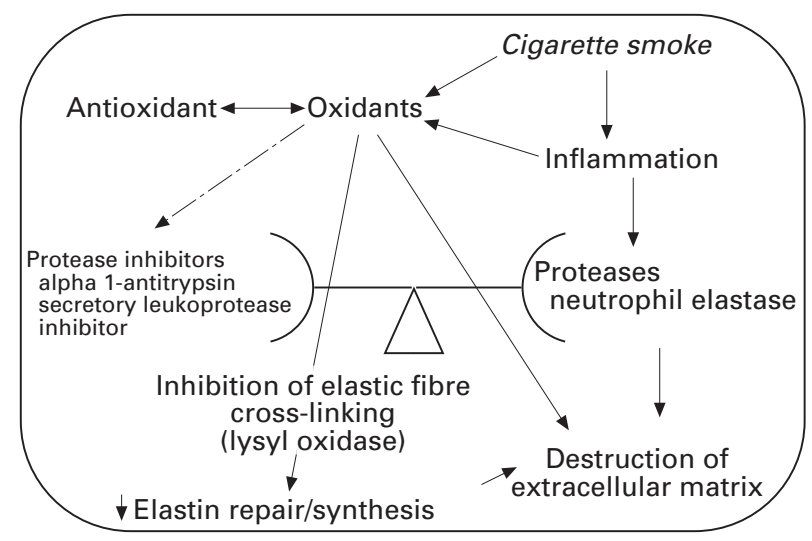

Figure 1 Protease-antiprotease balance and oxidantFigure 1 Protease-antip
antioxidant balance.

ponents of the lung extracellular matrix such as elastin and collagen, or modify the matrix to make it more susceptible to protease attack (fig 1 ).

The systemic effects of these changes can be detected in a number of ways. Morrow et al have recently found increased levels of prostaglandin $\mathrm{F}_{2}$ like compounds $\left(\mathrm{F}_{2-}\right.$ isoprostanes) in the plasma of smokers, indicating that smoking causes lipid peroxidation in vivo. ${ }^{11}$ Rahman $e$ al found a decreased antioxidant capacity of plasma in smokers, the decrease being most marked one hour after smoking. Thus, cigarette smoke may deplete the antioxidant capacity. ${ }^{12}$ There is consequently good theoretical and experimental evidence, as well as some theoretical and experimental evidence, as well as some
clinical support, pointing to the importance of the oxclinical support, pointing to the importance of the ox-
idant-antioxidant imbalance in the pathogenesis of pulmonary emphysema. In addition, there have been suggestions that genetic susceptibility to oxidative stress may have a role in the pathogenesis of other diseases such as diabetes mellitus ${ }^{13}$ and its vascular complications, ${ }^{14}$ as diabetes mellitus ${ }^{13}$ and

We shall review the introductory article in the context of all the known genetic associations of COPD.

\section{Introductory article}

Smith and Harrison investigated the genetic polymorphism of an important xenobiotic metabolising enzyme, microsomal epoxide hydrolase. There are four common microsomal epoxide hydrolase alleles, depending on the presence or absence of two point mutations in the coding gene. The presence of one mutation results in a "slow" allele, while the presence of the other gives rise to a "fast" allele. The rare occurrence of both mutations together produces the enzyme with normal activity. The homozygous state for the slow allele results in a phenotype of very slow microsomal epoxide hydroin a phenotype

Using a PCR-based genotyping assay, Smith and Harrison investigated whether polymorphisms in the gene for microsomal epoxide hydrolase were linked with susceptibility to COPD and emphysema. The mechanism proposed was that, since this enzyme system is involved in the metabolism of highly reactive epoxide intermediates, slow metabolisers might experience intermediates, slow metabolisers might experience greater oxidative stress from cigarette smoke and so
develop lung disease. Four groups were studied: blood develop lung disease. Four groups were studied: blood
donor controls, asthma controls, patients with COPD, and patients with lung cancer. The group with lung cancer was then subdivided into those with and those without emphysema by examination of the resection specimens from the pathology archives of Edinburgh
University. No clinical data were available for the lung cancer patients but lung function was presumably quite well preserved or they would not have undergone surgery.

This rather odd study design suggests a possible change of direction during the course of the research. It may be that the investigators started by seeking a genetic susceptibility to lung cancer (reactive epoxides are carcinogenic) with negative results, but stumbled on an association between slow metabolisers and COPD. Whatever the primary aim, the outcome was interesting. In brief, the COPD and "emphysema" groups contained significantly more homozygous mutants for the exon 3 (slow) polymorphism than the controls.

Some caution is needed over the interpretation of these findings. While they may indicate a true and novel causal association, the study population was small and the findings could be due to chance. They clearly need to be confirmed in other study populations. Furthermore, the "emphysema" group was unusual, being defined from the morbid anatomy of lung samples resected for cance resected for cancer. While this is the "purest" way to make such a diagnosis, it provides no clinical information. If these subjects simply had histological evidence of mild emphysema, they may not be satisfactorily representative of smokers in general who are susceptible to COPD.

A second concern is whether biochemical pathways affected by microsomal epoxide hydrolase are actually involved in the pathogenesis of emphysema. Cigarette smoke certainly contains free radicals and multiple other chemicals capable of generating reactive epoxides, and some of these can certainly damage nucleic acids, proteins and lipids. It is not clear, however, whether these processes are important in vivo, how they affect the protease/antiprotease balance or oxidant/antioxidant balance, nor whether epoxide hydrolase is an important rate limiting step in such a process.

The hypothesis that oxidant/antioxidant imbalance is due to polymorphisms of the gene for microsomal epoxide hydrolase is nevertheless an interesting one which deserves further investigation. There are many possible genetic mechanisms for undue susceptibility to cigarette smoke, and it is worth reviewing the range of these in order to put this new observation in perspective.

\section{Genetic contributions to COPD}

XENOBIOTIC METABOLISM

Genetically determined variation in xenobiotic detoxification/biotransformation has attracted interest recently as a possible mechanism for observed differences in susceptibility to various conditions-for example, idiosyncratic reactions to pharmacological agents and smoking induced lung co phers ${ }^{16} 17$ A detailed discussion of the metabolic process of detoxification of xenobiotics is beyond the scope of this review. Briefly, the major pathway of metabolism involves two main types of enzymes: the phase I cytochrome P-450 mediating oxidative metabolism, and phase II conjugating enzymes such as glutathione S-transferases. A number of xenoto highly reactive intermediates such as epoxides by the to highly reactive intermediates such as epoxides by the
cytochrome P450 system. These resultant metabolites cytochrome P450 system. These resultant metabolites
may be cytotoxic, mutagenic, and/or carcinogenic. The enzymatic conversion of these metabolites to inactive intermediates is therefore protective.

Epoxides can be detoxified principally by glutathione S-transferases (GST) or epoxide hydrolases. The rel- 


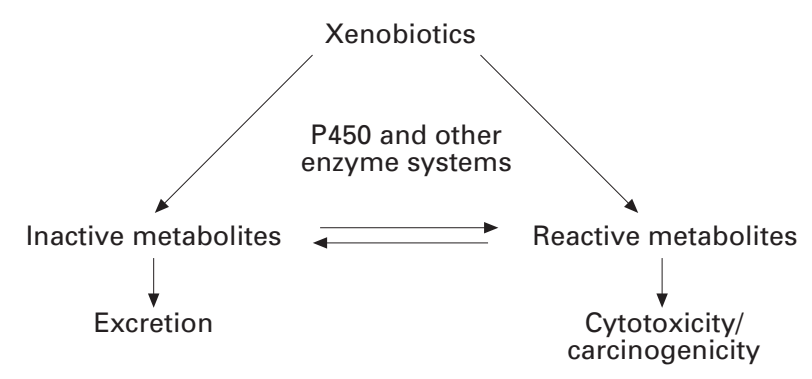

Figure 2 Xenobiotic metabolism: activation-inactivation Figure 2
balance.

ative balance between activation and inactivation is thought to underlie susceptibility to the noxious effects of various xenobiotics (fig 2). For example, altered phenotypes and genotypes in the cytochrome P450 isoforms CYP1A1 have been reported to be associated with smoking-induced lung cancer and other cancers. ${ }^{18}$ Defective glutathione S-transferases caused by the GST M1 null genotype have also been linked to an increased $M 1$ null genotype have also been linked to an increased
risk of developing lung cancer, ${ }^{19}$ although the results of risk of developing lung cancer, ${ }^{19}$ although the results of
studies conducted in different ethnic groups have not always been consistent. In addition, individuals with the susceptible genotypes of CYP1A1 with deficien GST $M 1$ were reported to be at remarkably high risk in a Japanese population..$^{20}$ This topic has recently been reviewed by Smith and associate ${ }^{21}$ and Raunio et al ${ }^{22}$ Although the liver plays a major role in xenobiotic metabolism, other organs (including lungs, kidneys and the gastrointestinal tract) have also been shown to be potential sites of metabolism. ${ }^{2}$

The introductory article is the first to suggest the involvement of genetic susceptibility to oxidative stress in the development of COPD. Previous studies on oxidant-antioxidant imbalance in COPD have focused largely on reactive oxygen species or oxidative molecules largely on reactive oxygen species or oxidative molecules
such as superoxide anion, hydrogen peroxide and hysuch as superoxide anion, hydrogen peroxide and hy-
droxyl radical, nitrogen dioxide, and ozone as the offensive agents. Many have also concerned the "classic" antioxidant enzymes such as superoxide dismutase, catalase, and glutathione peroxidase, as well as non-en- zymatic antioxidants such as $\alpha$-tocopherol, $\beta$-carotene, ascorbate, or glutathione. Since epoxide hydrolases catalyse hydrolysis of epoxides formed as a result of oxidative metabolism mediated by cytochrome P450, it is conceivable that this important enzyme does play a significant role in preventing the tissue injury caused by nifcant role in preventing the tissue injury caused by ifying enzymes such as glutathione S-transferases. In fact, some researchers, including the authors of the introductory article, have shown possible associations of COPD with polymorphisms in GST $M 1^{24}$ or GST P1. ${ }^{25}$

The expression and activity of enzymes are influenced not only by genetic factors but also by various chemicals in the environment through induction and competitive inhibition. Furthermore, the clinical effect will depend not only on the kinetics of metabolism but also on the not only on the kinetics of metabolism but also on the
major site of action. Local expression in lungs might well be as important as hepatic metabolism, and so the relationship of the activity of a given enzyme and its clinical consequences is likely to be complex.

DEFICIENCY OF ANTIPROTEASE SCREEN

Alpha $a_{1}$-antitrypsin deficiency

A number of genetic factors have been proposed to increase the risk for developing COPD, but only a few have been confirmed to be clinically significant. The most important is $\alpha_{1}$-antitrypsin deficiency; the odds ratio for the development of COPD in association with the homozygous $\mathrm{ZZ}$ phenotype (presence versus absence) has been calculated at more than 30 (table 1). As $\alpha_{1}$-antitrypsin is a potent inhibitor of neutrophil elastase, the recognition of this association has led to an elastase-antielastase hypothesis (or, more broadly, a protease-antiprotease hypothesis) as a pathogenic exprotion for pulmonary emphysema (fig 1). planation for pulmonary emphysema (fig 1 ). However as the frequency of this homozygosity is relatively low even in Caucasian populations, the deficiency accounts for less than $1 \%$ only of all patients with COPD, although some estimates have been higher. ${ }^{26}$ Furthermore, $\alpha_{1}$-antitrypsin deficiency with the PiZZ phenotype is not necessarily associated with COPD and many such

\begin{tabular}{|c|c|c|c|c|c|c|c|c|c|}
\hline & Total & $M M$ & MS & $M Z$ & $Z Z$ & SS & $S Z$ & Author & Location \\
\hline Controls & $\begin{array}{r}2054 \\
280 \\
106 \\
642 \\
721 \\
930 \\
91 \\
114 \\
1380 \\
6318\end{array}$ & $\begin{array}{c}1828 \\
254 \\
94 \\
583 \\
644 \\
835 \\
81 \\
98 \\
1213.5 \\
5630.5\end{array}$ & $\begin{array}{c}82 \\
17 \\
8 \\
42 \\
57 \\
60 \\
5 \\
8 \\
110.5 \\
389.5\end{array}$ & $\begin{array}{r}85 \\
8 \\
3 \\
8 \\
14 \\
14 \\
21 \\
2 \\
6 \\
64 \\
181\end{array}$ & $\begin{array}{l}1 \\
0 \\
0 \\
2 \\
0 \\
0 \\
0 \\
0 \\
0 \\
3\end{array}$ & $\begin{array}{l}2 \\
0 \\
0 \\
0 \\
0 \\
\\
1 \\
1 \\
4\end{array}$ & $\begin{array}{r}4 \\
0 \\
0 \\
1 \\
0 \\
\\
\\
0 \\
5 \\
10\end{array}$ & $\begin{array}{l}\text { Gulsvik (1979) } \\
\text { Bencze (1980) } \\
\text { Talamo (1972) } \\
\text { Bartman (1985) } \\
\text { Cox (1976) } \\
\text { Shigeoka (1976) } \\
\text { Barnett (1975) } \\
\text { Kueppers (1977) } \\
\text { Lieberman (1976) }\end{array}$ & $\begin{array}{l}\text { Oslo, Norway } \\
\text { Munich, Germany } \\
\text { Mass, USA } \\
\text { Bonn, Germany } \\
\text { Toronto, Canada } \\
\text { New York, USA } \\
\text { North Caroline, USA } \\
\text { Minnesota, USA } \\
\text { California, USA }\end{array}$ \\
\hline $\begin{array}{l}\text { Total } \\
\text { OR* } \\
\text { OR vs MM }\end{array}$ & $\begin{array}{r}149 \\
76 \\
99 \\
526 \\
123 \\
502 \\
107 \\
114 \\
190 \\
965 \\
350 \\
3201\end{array}$ & $\begin{array}{r}123 \\
70 \\
84 \\
429 \\
101 \\
442 \\
87 \\
97 \\
146 \\
275 \\
1854 \\
0.59\end{array}$ & $\begin{array}{r}14 \\
0 \\
8 \\
34 \\
7 \\
35 \\
6 \\
5 \\
10 \\
97 \\
22 \\
238 \\
1.22 \\
1.10\end{array}$ & $\begin{array}{r}7 \\
2 \\
4 \\
31 \\
6 \\
14 \\
10 \\
9 \\
26 \\
74 \\
35 \\
218 \\
2.48 \\
2.42\end{array}$ & $\begin{array}{c}1 \\
2 \\
1 \\
5 \\
8 \\
1 \\
2 \\
3 \\
5 \\
18 \\
12 \\
58 \\
38.85 \\
40.49\end{array}$ & $\begin{array}{l}0 \\
0 \\
0 \\
0 \\
0 \\
\\
0 \\
0 \\
3 \\
3 \\
6 \\
2.44 \\
2.67\end{array}$ & $\begin{array}{c}1 \\
0 \\
0 \\
18 \\
0 \\
\\
0 \\
2 \\
3 \\
3 \\
27 \\
7.92 \\
8.54\end{array}$ & $\begin{array}{l}\text { Gulsvik }(1979) \\
\text { Bencze (1980) } \\
\text { Talamo }(1972) \\
\text { Bartman }(1985) \\
\text { Cox }(1976) \\
\text { Shigeoka (1976) } \\
\text { Barnett }(1975) \\
\text { Kueppers (1977) } \\
\text { Janus (1988) } \\
\text { Lieberman (1986) } \\
\text { Mitmann (1974) }\end{array}$ & $\begin{array}{l}\text { Oslo, Norway } \\
\text { Munich, Germany } \\
\text { Mass, USA } \\
\text { Bonn, Germany } \\
\text { Toronto, Canada } \\
\text { New York, USA } \\
\text { North Caroline, USA } \\
\text { Minnesota, USA } \\
\text { Melloourne, Australia } \\
\text { California, USA } \\
\text { California, USA }\end{array}$ \\
\hline
\end{tabular}


people remain healthy in the absence of a smoking history into their sixth and seventh decades. ${ }^{27}$

The heterozygous state of $\alpha_{1}$-antitrypsin deficiency has also been implicated as a possible risk factor fo COPD; the odds ratio for developing COPD in MZ hetezygotes heterozygotes nor homozygotes) has been reported by some investigators to range from 1.5 to 5.0 in a review by Standford $e t a l^{28}$ (see also table 1). Furthermore, Tarján and colleagues have recently reported accelerated declines in expiratory flow rates and diffusing capacity, as well as increases in total lung capacity and residua volume, in PiMZ heterozygous subjects in a longitudinal study ${ }^{29}$ In practice, however,

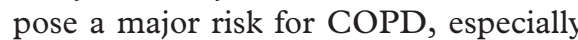
in the absence of smoking. Indeed, several studies in randomly selected populations have failed to demonstrate a definite association between $\mathrm{MZ}$ phenotype and COPD, ${ }^{30-34}$ one having had a power of $95 \%$ to detect a difference in $\mathrm{FEV}_{1} / \mathrm{FVC} \%$ as low as $3 \%$

Mutation of the flanking sequence of the $\alpha_{1}$-antitrypsin gene

A mutation of the $3^{\prime}$ flanking sequence of the $\alpha_{1}$ antitrypsin gene has been associated with COPD in a few studies..$^{356}$ The odds ratios for developing COPD (or emphysema) in association with this mutation (present versus absent) were calculated to be 4.3 and 3.2, respectively. This condition is different from $\alpha_{1}$-antitrypsin deficiency in that the sequence which codes for the protein itself is normal and the basal serum level of $\alpha_{1}$-antitrypsin is not reduced. Kalsheker et al suggested that the mutation might diminish the response of the $\alpha_{1}$-antitrypsin gene to interleukin 6 and thus suppress the acute phase response of $\alpha_{1}$-antitrypsin. ${ }^{37}$ This acute response is thought to counter the increased proteolytic burden at the region of injury induced by inflammation.

Alpha $a_{1}$-antichymotrypsin deficiency

The deficiency of another serine protease inhibitor, $\alpha_{1}$ antichymotrypsin, has also been shown to be associated with COPD. This counteracts the adverse enzymic effects of neutrophil cathepsin G, mast cell chymase, and chymotrypsin. Poller et al detected this deficiency in four of 100 patients with COPD but in none of 100 healthy controls. ${ }^{38}$ However, there seems to be a wide healthy controls. ${ }^{38}$ However, there seems to be a wide variation in the prevalence of this deficiency between
different populations, ${ }^{39}$ as is the case for $\alpha_{1}$-antitrypsin deficiency, and this abnormality is unlikely to account for a large proportion of patients who develop COPD.

TUMOUR NECROSIS FACTOR- $\alpha$ GENE POLYMORPHISM

A recent study from Taiwan has reported an association between chronic bronchitis and a polymorphism at the -308 position of the tumour necrosis factor $\alpha(\mathrm{TNF} \alpha)$ gene. ${ }^{40}$ This polymorphism gives rise to two alleles, TNF1 and TNF2. The investigators found that the less common allele, TNF2, which was associated with higher basal and induced expression of $\mathrm{TNF} \alpha$, was more prevalent in patients with chronic bronchitis. They suggested there was an augmented inflammatory process TNF $\alpha$ expression, and hence the development of chronic bronchitis.

The patient group consisted of 42 male adults who had histories of chronic or recurrent productive cough for more than two successive years. There was also airflow limitation defined as $\mathrm{FEV}_{1}$ of $<80 \%$ predicted and FEV /FVC $<69 \%$ predicted. Thirteen patients $(31 \%)$ were non-smokers. No occupational histories were given, and the 13 may have included patients with chronic asthma. Further studies in other populations will be needed to confirm this interesting association.

\section{OTHER FACTORS}

Inherited disorders of connective tissue such as Marfan syndrome ${ }^{41}$ Ehlers-Danlos syndrome, ${ }^{42}$ and cutis laxa ${ }^{43}$ are reported to be associated with a number of pulmonary diseases including emphysema. Abnormal elastic tissue in lungs has been found in necropsy material from infants with Marfan syndrome, ${ }^{41}$ and this may explain the association.

Blood group-related phenotypes including $\mathrm{ABO}$ blood group, $\mathrm{ABH}$ secretor/non-secretor, and Lewis positive/negative status have also been focuses of attention, but study results have been inconclusive ${ }^{44-47}$

The sex and race of the subjects have also been implicated as possible factors of relevance. The prevalences of COPD and chronic bronchitis are said to be higher in men than in women, for equivalent cigarette consumption, ${ }^{48}$ and some studies have shown a greater relative loss of lung function in men than in women ${ }^{4}$ sceptible than men to the adverse effects of smoking on lung function. ${ }^{50}$ Furthermore, some studies have suggested that white males may be more prone to developing

\section{LEARNING POINTS}

* Only $10-20 \%$ of cigarette smokers develop symptomatic COPD, implying undue susceptibility compared with the remainder of the population at large.

* Alpha ${ }_{1}$-antitrypsin deficiency, which is the only fully established genetic risk factor, accounts for less than $1 \%$ of all cases of COPD.

* Polymorphisms for the genes controlling xenobiotic metabolism (hence oxidant-antioxidant balance) may explain some of the observed differences in susceptibility to various conditions caused by environmental factors, including COPD.

* Elucidation of additional genetic risk factors may provide useful insights into the pathogenesis of COPD, but clinical benefits are not yet apparent.

* The absence of demonstrable risk factors in the individual for developing COPD or lung cancer should not deter physicians from persuading smokers to quit the habit. 
COPD than non-white males, ${ }^{51}$ but neither sex nor race are likely to be major genetic determinants of susceptibility to tobacco smoke.

1 Siafakas NM, Vermeire P, Pride NB, et al on behalf of the Task
Force. Optimal assessment and management of chronic obstructive Force. Optimal assessment and management of chronic obstructive

of chronic airflow obstruction. Webster PM, Lorimer EG, Man SFP, et al. Pulmonary function in Respir Dis 1979;119:223-8.
ankins D, D

C, Zamel N, et al. Pulmonary function in identica Wubert HB Fart. Am Rev Respir Dis 1982;125:119-21. influences on pulmonary function in adult twins. Am Rev Respir $D i$ 1982;125:409-15.

6 Redline S, Tishler PV, Lewitter FI, et al. Assessment of genetic and nongenetic influences on pu
Respir Dis 1987;135:217-22.

7 Laurell CB, Eriksson S. The electrophoretic $\alpha_{1}$-globulin pattern of serum in $\alpha_{1}$-antitrypsin deficiency. Scand $\mathcal{F}$ Clin Invest 1963;15:132. for microsomal epoxide hydrolase and susceptibility to emphysema. Lancet 1997;350:630-3.

9 Buhl R, Meyer A, Vogelmeier C. Oxidant-protease interaction in the 10 Rahman I, MacNee W. Oxidant/antioxidant imbalance in smokers and chronic obstructive pulmonary disease. Thorax 1996;51:348-50.
11 Morrow JD, Frei B, Longmire AW, et al. Increase in circulating products of lipid peroxidation (F2-isoprostanes) in smokers. $N$ Engl F Med
1995;332:1198-203 Rahman I, Morrison D, Donaldson K, et al. Systemic oxidative stress
in asthma, COPD, and smokers. Am $\mathcal{F}$ Respir Crit Care Med 1996;

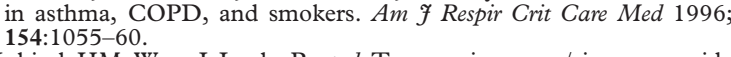
3 Kubisch HM, Wang J, Luche R, et al. Transgenic copper/zinc superoxide dismutase modulates susceptibility to type I
Sci USA 1994;91:9956-9. 14 Ruiz J. Diabetes mellitus and the late complications: influence of the
genetic factor. Diabetes Metabolism 1997;23(Suppl 2):57-63. 5 Ikebe S, Tanaka M, Ozawa T. Point mutations of mitochondrial genome in Parkinson's disease. Mol Brain Res 1995;28:281-95. West WL, Knight EM, Pradhan S, et al. Interpatient variability: genetic
predisposition and other genetic factors. F Clin Pharmacol $1997 ; 37$
$635-48$.

7 Seidegård J, Ekström G. The role of human glutathione transferases Health Perspect 1997;105(Suppl 4):791-9.
Kawaiji K, Eguchi H, Nakachi K, et al. Association of CYP1A1 germ line polymorphisms with mutations of the $p 53$ gene in lung cancer. 9 Zhong S, Howie AF, Ketterer B, et al. Glutathione S-transferase mu locus: use of genotyping and phenotyping assays to assess association with lung cancer susceptibility. Carchogenesis 1991;12:1533-7. phisms of the CYPIA

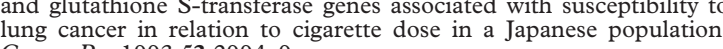
Cancer Res 1993;53:2994-9.
Smith CAD, Smith G Wolf

Smith CAD, Smith G, Wolf CR. Genetic polymorphisms in xenobiotic 22 metabolism. Eur F Cancer 1994;30A:1921-5. morphisms in carcinogen-activating and inactivating enzymes and 23 Krishna DR, Klotz U. Extrahepatic metabolism of drugs in humans Clin Pharmacokinet 1994;26:144-60.
24 Harrison DJ, Cantlay AM, Rae F, et al. Frequency of glutathione Stransferase M1 deletion in smokers with emphysema and lung cancer. Human Exp Toxicol 1997;17:356-60.
Harries LW, Stubbins MJ, Forman D, et al. Identification of genetic Harries LW, Stubbins MJ, Forman D, et al. Identification of genetic
polymorphism at the glutathione S-transferase Pi locus and association 26 Mittman C, Barbela T, Lieberman J. Alpha 1 -antitrypsin deficiency as an indicator of susceptibility to pulmonary disease. 7 Occup Med 1973 15:33-8.
Black LF, Back LF, Kueppers F. Alpha -antitrypsin deficiency in nonsmokers. Am Rev Respir Dis 1978;117:421-8.
Standford AJ, Weir TD, Par PD

Standford AJ, Weir TD, Par PD. Genetic risk factors for chronic
obstructive pulmonary disease. Eur Respir 7 1997:10:1380-91.

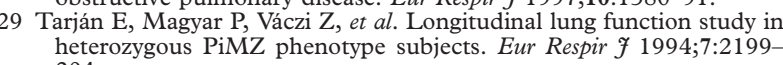
heterozygous PiMZ phenotype subjects. Eur Respir f 1994;7:2199McDonagh DJ, Nathan ST, Knudson RJ, et al. Assessment of alpha-1-
antitrypsin deficiency heterozygosity as a risk factor in the etiology of antitrypsin deficiency heterozygosity as a risk factor in the etiology of emphysema. F Clin Invest 1979;63:299-309.
Morse JO, Lebowitz MD, Knudson RJ, et al. A community study of the relation of alpha 1 -antitrypsin levels to obstructive lung diseases.
N Engl F Med 1975;292:278-81. 32 Webb DR, Hyde RW, Schwartz RH, et al. Serum $\alpha_{1}$-antitrypsin variants: prevalence and clinical spirometry. Am Rev Respir Dis 1973;108
$918-25$. Cole RB, Nevin NC, Blundell G, et al. Relation of alpha-1-antitrypsin
phenotype to the performance of pulmonary function tests and to the phenotype to the performance of pulmonary function tests and to the
prevalence of respiratory illness in a working population. Thorax 1976; 31:149-57. Bruce RM, Cohen BH, Diamond EL, et al. Collaborative study to asses
risk of lung disease in Pi MZ phenotype subjects. Am Rev Respir Dis Kalsheker NA, Hodgson IJ, Watkins GL, et al. Deoxyribonucleic acid (DNA) polymorphism of the $\alpha_{1}$-antitrypsin gene in chronic lung dilea W, Meisen C, Olek K. DNA polymorphisms of the $\alpha_{1}$-antitrypsin
Poller gene region in patients with chronic obstructive pulmonary disease. Eur Y Clin Invest 1990;20:1-7.

Kalsheker NA, Morgan K. Regulation of the $\alpha_{1}$-antitrypsin gene and a Respir Crit Care Med 1994;150:S183-9.
Rorler W, Faber J-P Scholz S, et al Poller W, Faber J-P, Scholz S, et al. Mis-sense mutation of $\alpha_{1}$-anti-
chymotryysin gene associated with chronic lung disease. Lancet 1992;
339:1538.

39 Samilchuk EI, Chuchalin AG. Mis-sense mutation of $\alpha_{1}$-antichymotrypsin gene and chronic lung disease. Lancet 1993;342:624.
Huang S-L, Su C-H, Chang S-C. Tumor necrosis factor- $\alpha$ gene polymorphism in chronic bronchitis. Am $\mathcal{Y}$ Respir Crit Care Med 1997;156:
1436-9. Reye RDK, Bale PM. Elastic tissue in pulmonary emphysema in Marfan 42 Cupo LN, Pyeritz RE, Olson JL, et al. Ehlers-Danlos syndrome with abnormal collagen fibrils, sinus of Valsalva aneurysms, myocardial infarction, panacinar emphysema and cerebral heterotopias. Am $\mathcal{F}$
Med 1981;71:1051-8. Med 1981;71:1051-8.
Merten DF, Rooney R. Progressive pulmonary emphysema associated with congenital generalized elastolysis (cutis laxa). Radiology 1974; 113:691-2. Yu P, Chan-Yeung M, et al. Lack of relationship between ABH secretor status and lung function in pulp mill workers. Am Rev Respir Dis 1982;126:1089-91.
auffmann F, Kleisbauer JP, Cambon-de Mouzon A, et al. Genetic Kauffmann F, Kleisbauer JP, Cambon-de Mouzon A, et al. Genetic
markers in chronic air-flow limitation: a genetic epidemiologic study. Am Rev Respir Dis 1983;127:263-9. al. An index of risk for obstructive airways disease. Am Rev Respir Dis 1982;125:144-51.

Katmann F, Frette C, Q-T Pham, et al. Associations of blood group

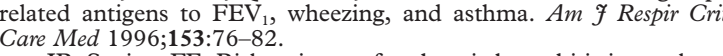

48 Tager IB, Speizer FE. Risk estimates for chronic bronchitis in smokers:
a study of male-female differences. Am Rev Respir Dis 1976;113: Dockery DW, Speizer FE, Ferris BG Jr, et al. Cumulative and reversible effects of life-time smoking on simple tests of lung function in adults. Am Rev Respir Dis 1988;137:286-92.
Prescott E, Bierg AM, Andersen PK, et al. Gender difference in smoking effects on lung function and risk of hospitalization for COPD: results
from a Danish longitudinal population study. Eur Respir F 1997;10:
$822-7$. 51 Stebbings JH Jr. A survey of respiratory disease among New York City Res 1973;6:147-58. 